URNAS FUNERÁRIAS LAGO AMAÑA, MÉDIO SOLI AMAZONAS: CONTEXTOS, G E PROCESSOS DE CONSERI 


\section{URNAS FUNERÁRIAS NO LAGO AMAÑA, MÉDIO SOLIMÕES, AMAZONAS: CONTEXTOS, GESTOS E PROCESSOS DE CONSERVAÇÃO}

\section{BERNARDO LACALE SILVA DA COSTA}

InSTITUTO DE DESENVOLVIMENTO SUSTENTÁVEL MAMIRAUÁ, BRASIL

$$
\text { A N N E RA P P P Y - D A N I E L }
$$

UNIVERSIDADE FEDERAL DO OESTE DO PARÁ, BRASIL

$$
\text { J A QU E L I N E G OM ES }
$$

INSTITUTO DE DESENVOLVIMENTO SUSTENTÁVEL MAMIRAUÁ, BRASIL

$$
\text { E D U A R D O GÓ E S N E V ES }
$$




\title{
URNAS FUNERÁRIAS NO LAGO AMANÃ, MÉDIO SOLIMÕES, AMAZONAS: CONTEXTOS, GESTOS E PROCESSOS DE CONSERVAÇÃO
}

\section{Resumo \\ A região do Lago Amanã, próximo à confluência dos rios Japurá e Solimões é ainda pouco conhecida arqueologicamente. Desde 2006, no entanto, levantamentos e escavações vêm sendo ali realizados com o apoio do Instituto de Desenvolvimento Sustentável Mami- rauá (IDSM). Nesse artigo serão apresentados alguns dados, ainda incipientes, sobre os contextos funerários da região e os potenciais do material encontrado. Os resultados obtidos a partir do estudo de algumas urnas funerárias dos sítios Bom Jesus do Baré e São Miguel do Cacau indicam práticas funerárias particulares à região. A presença de material de acompanhamento dentro dos vasos, a possibilidade de enterramentos primários, a proximidades das urnas nos sítios a forma e as características dos vasos, levam a pensar num alto grau de uniformidade durante a fase Caiambé, relacionada à Tradição Borda Incisa ou série Barrancóide. \\ Palavras-Chave: Urnas funerárias, Lago Amanã, tafonomia. \\ FUNERARY URNS IN LAKE AMANÃ, MIDDLE SOLIMÕES, AMAZONAS: CONTEXTS, CONSERVATION PROCESSES AND GESTURES}

\begin{abstract}
The Lake Amanã, located near the junction of the Japurá and the Solimões rivers, is in a still poorly known archaeological region. However, since 2006, surveys and excavations have been conducted with the support of the Instituto de Desenvolvimento Sustentável Mamirauá (IDSM). This paper presents preliminary data on the funerary contexts of that region as well as on the potentials of the recovered material. The results obtained from the study of some funerary urns from Bom Jesus do Baré and São Miguel do Cacau indicate unique burial practices. The presence of accompanying mortuary furniture inside the vessels, the possibility of being primary burials, the proximity of the urns within the sites, and the vessels' characteristics suggest a high degree of uniformity during the Caiambé phase, related do the Incised Rim Tradition or Barrancoid Series.
\end{abstract}

Keywords: Funerary urns, Lake Amanã, taphonomy. 


\section{LES URNES FUNERAIRES DU LAC AMANÃ, LE MOYEN SOLIMÕES, AMAZONAS: CONTEXTES, LES PROCESSUS DE CONSERVATION ET LES GESTES}

\section{Résumé}

La région du Lac Amanã, proche de la confluence des fleuves Japurá et Solimões, est encore peu connue archéologiquement. Toutefois, depuis 2006 des prospections et des fouilles ont été menées avec le soutien de l'Instituto de Desenvolvimento Sustentável Mamirauá (IDSM). Dans cet article seront présentées quelques données, préliminaires, sur les contextes funéraires de la région et le potentiel du matériel retrouvé. Les résultats de l'étude de quelques urnes des sites de Bom Jesus do Baré e São Miguel do Cacau indiquent des pratiques funéraires propres à la région. La présence de matériel d'accompagnement dans les urnes, la possibilité d'inhumations primaires,la proximité des vases et leurs caractéristiques, suggèrent un haut degré d'uniformité pendant la Phase Caiambé, la Tradition Bord Incisé ou Barrancoïde.

Mots-Clés : Urnes funéraires, Lac Amanã, taphonomie. 


\section{INTRODUÇÃO}

Nos últimos anos, os avanços realizados pela arqueologia amazônica têm permitido que se superem as antigas oposições, típicas da segunda metade do século $\mathrm{XX}$, embasadas em interpretações contrárias, por exemplo, entre a existência ou não de sociedades complexas, sobre o desenvolvimento da agricultura e até mesmo sobre a origem exógena de suas antigas populações (Evans \& Meggers 1968; Lathrap 1970; Neves 1998;1999). Atualmente percebe-se que a variedade de contextos na Amazônia é muito ampla e que a imensidão da região associada à irregularidade das pesquisas no último século, não permite que um quadro completo do processo de ocupação humana seja elaborado, pois a cada ano dados inéditos trazem novas reflexões; mesmo assim aos poucos surge o esboço de uma Amazônia précolonial que tem como principal característica a diversidade (Erickson 2003; Heckenberger 2001; Neves 2011a; 2011 b; Rostain 2010; Schaan 2004).

Embora a necessidade de estudos de formação do contexto de sítios arqueológicos e de áreas de atividades específicas dentro dos sítios venha sendo bastante debatida nos últimos 30 anos na teoria arqueológica (Binford 1991; Schiffer 1987), as análises são frequentemente limitadas ao material mais abundante ou mais perceptível em campo. No ambiente amazônico, a cerâmica geralmente é o vestígio de destaque, pois tem maior grau de preservação nos sítios arqueológicos, se tornando, portanto o arcabouço empírico para a construção de quadros interpretativos de ocupação através de análises sobre a manufatura, o uso e a dispersão desses materiais (Machado 2007).

Apesar disso, nos últimos anos outras variáveis passaram a ser importantes na arqueologia amazônica, principalmente no que se refere ao entendimento da amplitude das modificações que as antigas populações imprimiram no ambiente. Uma delas é a origem e formação da Terra Preta de Índio (TPI) ou Terra Preta Antropogênica (TPA) (Teixeira et al. 2009; Woods 2009; Kern et al. 2009; Costa et al. 2009), com trabalhos específicos para formação dos sítios arqueológicos (Rebellato 2007). Seguindo essa tendência, o estudo de vestígios botânicos, microscópicos, macroscópicos e genéticos também tem se desenvolvido muito, quebrando antigos paradigmas que enfatizavam em demasia o poder de destruição dos processos tafonômicos. Finalmente, o uso de outras variáveis, tais como a distribuição de vestígios de áreas de habitação pelos sítios, tem trazido informações importantes que, aliadas aos dados cerâmicos, contribuem para o mapeamento da variabilidade cultural no passado amazônico (Neves 2010).

Esse novo quadro de pesquisas permite explorar outros tipos de vestígios, que por vezes podem trazer informações adicionais sobre a formação dos contextos arqueológicos. No entanto, o estudo e eventual interpretação desses "outros" vestígios exigem um conhecimento prévio sobre suas potencialidades de análises e seus processos de preservação/deterioração.

Muitos contextos arqueológicos na Amazônia são conhecidos pela prática de sepultamento em urnas cerâmicas 
(Marajoara, Aristé, Paredão, Guarita, Maracá, etc.). Vários estudos já foram realizados abordando os vasos em si, as técnicas de manufatura, suas utilizações, as estruturas decorativas, mas pouquíssimos estudos cruzam esses dados de contextos funerários com a identificação de práticas e gestos funerários (Barreto 2008; Schaan 2003). De acordo com Barreto (2008:39), os rituais funerários - e todos os gestos neles envolvidos - implicam uma série de estágios onde elementos visuais são usados e reconhecidos pelas sociedades, e nos quais o tempo dispensado nos funerais e o tipo de enterramento definitivo estão profundamente relacionados a cosmologias específicas, sendo assim, pouco susceptíveis a "modismos" (Müller \& Souza 2011).

Apesar de pouco debatido na arqueologia amazônica, o estudo de sítios arqueológicos com vestígios ósseos humanos pode trazer muitas informações, além das tradicionais estimativas de idade, sexo e/ ou doenças dos indivíduos enterrados. A análise dos sepultamentos - e de tudo que neles estão contidos - pode esclarecer os gestos realizados durante o ritual funerário e os processos tafonômicos (Duday 2005; Machado 2006; Rapp Py-Daniel 2010). Como bem lembra Mendonça de Souza et al. (2001:487):

" $\mathrm{Na}$ maioria dos casos a perda de segmentos anatômicos de esqueletos originalmente organizados, a dispersão de ossos de um mesmo esqueleto, inversões ou migrações de partes de um mesmo indivíduo, ou de um mesmo osso nas camadas arqueológicas, assim como sinais de erosões, compressões, quebras, queimas, incrustações, descolorações, e outros indícios tafonômicos, permitem discutir e reconstituir processos pós-deposicionais. Alguns destes são processos cadavéricos específicos, naturalmente associados à morte; outros dizem respeito às mudanças que afetam genericamente o sítio; ainda que possam estar mais obviamente demonstrados numa estrutura funerária, outros são associáveis à ação antrópica pré ou pós-deposicional."

O estudo de material ósseo e as análises de contexto funerário considerando principalmente os indivíduos enterrados ainda não é uma prática recorrente no Brasil (Mendonça et al. 2001). Isso acontece principalmente por duas razões: i) o estado de degradação avançado dos elementos ósseos, até sua completa decomposição; ii) falta de conhecimento sobre as possibilidades de análises que esse tipo de vestígio pode oferecer, até mesmo quando se encontram em condições friáveis.

As pesquisas arqueológicas no Lago Amanã, localizado próximo à confluência dos rios Solimões e Japurá ${ }^{1}$ (Figura 1), têm fornecido dados interessantes para essa discussão. Uma recorrência na região é a presença de concentrações de afloramentos de recipientes cerâmicos de grandes dimensões, com comunidades contemporâneas inteiras assentadas sobre elas². Em 2001, o antropólogo Glenn Shepard, ao visitar a região encaminhou ao IPHAN uma carta na qual relata:

"Durante a realização de pesquisas autorizadas na Reserva de Desenvolvimento Sustentável Amanã no período 9-23 de abril, 2001, junto 
com a equipe de Dr. Carlos Peres (University of East Anglia, Inglaterra) e Dra. Maria Nazareth F. da Silva (INPA), passei algumas horas na comunidade de Boa Esperança. Durante a breve visita, notei a presença inequívoca de urnas funerárias e outros restos arqueológicos de antigas culturas indígenas. Estas informações muito preliminares (fotografias serão enviadas como anexo em breve) estão sendo encaminhadas para o Instituto de Patrimônio Histórico e Artístico Nacional (IPHAN) na esperança de que o local poderia ser registrado e estudado em mais detalhe para resgatar os objetos e informações arqueológicas antes do que sejam destruídos ou danificados" (Shepard 2001:1).

O contexto arqueológico do Lago Amanã, apesar de sua riqueza e de algumas referências esporádicas em trabalhos prévios (Meggers \& Evans 1968), ainda continua pouco conhecido. Isso se dá pela carência de trabalhos de campo na região do médio rio Solimões e rio Japurá, que foram realizadas apenas por Peter Paul Hilbert (1962) e Wanda Hanke (1959) no fim da década de 1950 e retomadas posteriormente em trabalhos de arqueologia preventiva no final dos anos 1990. Esses hiatos nas pesquisas foram superados apenas em 2008 quando no âmbito do projeto "Plano de manejo do patrimônio arqueológico existente na $R D S$ Amanã, Estado do Amazonas"3, passaram a ser realizadas pesquisas sistemáticas através de levantamentos, mapeamentos e escavações de sítios. Por outro lado, pesquisas realizadas no rio $\mathrm{Ca}$ quetá ${ }^{4}$, na Colômbia, nas regiões de Araracuara e La Pedrera (Eden et al. 1984;
Herrera et al.1980-81; von Hildebrand 1976) mostram que essa região é habitada há pelo menos 9.000 anos, com evidências de formação de terra preta no início da era cristã (Cavelier et al. 1995).

Até o momento, 32 sítios arqueológicos foram identificados em torno do Lago Amanã e arredores (Figura 1); em 14 deles é possível inferir sobre grandes contextos funerários (Costa 2008). Uma cronologia preliminar para a área foi realizada através da análise cerâmica e de datações radiocarbônicas no sítio Boa Esperança $^{5}$ (Costa 2011; Gomes 2011). A ocupação da área se iniciou em meados do primeiro milênio antes de Cristo $(2500 \pm 50 \mathrm{BP}$ e $2410 \pm 40 \mathrm{BP})$ com materiais que guardam muitas semelhanças com as fases ${ }^{6}$ Açutuba e Pocó, encontradas, respectivamente, no médio e baixo Amazonas (Guapindaia 2008; Hilbert \& Hilbert 1980; Lima et al. 2006). Posteriormente, nos contextos mais superficiais, as cerâmicas apresentam elementos diagnósticos da fase Tefé da Tradição Polícroma da Amazônia (Hilbert 1968).

Nesse trabalho trataremos dos sítios Bom Jesus do Baré e São Miguel do Cacau (Figura 1). O primeiro está localizado próximo à cabeceira e na margem esquerda do lago; não demonstra camadas culturais marcadas e não possui solos modificados perceptíveis, mas apresenta muitos vasilhames cerâmicos concentrados em duas porções de sua área total. O sítio São Miguel do Cacau localiza-se à margem esquerda de um igarapé que deságua na porção inferior do lago e foi recentemente escavado. A partir do tratamento preliminar dos vestígios cerâmicos, o sítio vem sendo 


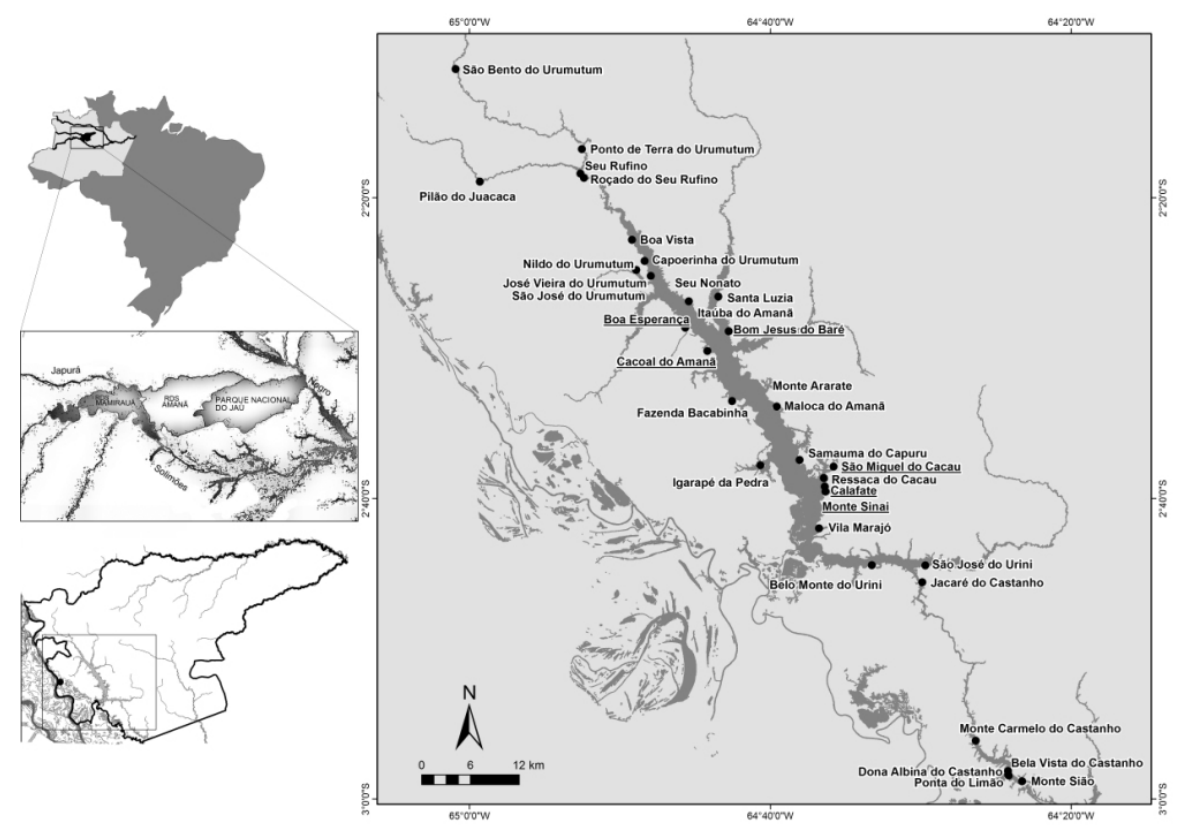

Figura 1 - Localização da área de estudo e os sítios identificados às margens do Lago Amanã, com destaque para aqueles mencionado no texto. Mapa: SIG/Instituto de Desenvolvimento Sustentável Mamirauá.

relacionado à fase Caiambé ${ }^{7}$ que foi definida por Hilbert nas proximidades da cidade de Tefé e inserida na Tradição Borda Incisa (Hilbert 1962; 1968). No Lago Amanã, tal fase parece estar relacionada ao período de intensificação de mudanças na paisagem, tais como a formação de terra preta, sendo ainda necessário evidenciar suas relações tanto com o antigo horizonte polícromo Pocó/Açutuba quanto à expansão da Tradição Polícroma da Amazônia.

Durante os levantamentos na RDS Amanã, vasos inteiros ou aparentemente inteiros, os quais era possível observar o afloramento de suas bordas, foram considerados inicialmente urnas. Entretanto, na Amazônia como um todo encontramos uma grande di- versidade em tamanho e forma de vasos inteiros enterrados que rapidamente são identificados como "urnas funerárias", mesmo não tendo sido comprovada essa função, isto é recorrente em todo Brasil (Müller \& Souza 2011). Na Amazônia há urnas funerárias e vasos enterrados, podendo ou não estar associados. De modo geral um argumento a favor de caracterizar a maior parte dos vasos, mas não todos, encontrados como "urna" são os contextos - vários vasos associados, formando áreas de prováveis cemitérios -, a recorrência de vestígios humanos no interior e a decoração/forma específica de alguns vasos quando considera-se períodos cronológicos mais restritos, como as fases arqueológicas - urnas funerárias de fases como Guarita, Maracá, Marajoara, 
Aristé, podem ser reconhecidas facilmente, pois suas formas e decoração são diagnósticas, os vasos foram feitos para uma função específica. Associados às urnas também temos vasos que possivelmente tinham funções distintas, eles podem ser maiores ou menores e em seu interior não se encontram vestígios humanos, porém é necessário que pesquisas envolvendo outros vestígios (sedimento, pólen, amidos, etc.) auxiliem na compreensão dessas associações. Nos dois sítios que serão apresentados neste trabalho será possível perceber que existe variabilidade inerente ao contexto, mas que também há padronização de alguns elementos. tanto no que se refere a localização espacial desses objetos, como nos tipos de vestígios encontrados no interior deles: vestígios ósseos, cerâmicos e solos antrópicos.

Nosso principal objetivo é levantar hipóteses sobre os possíveis processos de formação dos contextos funerários de ambos os sítios, através principalmente de observações gerais obtidas em campo e do início do tratamento dos vestígios em laboratório. Primeiramente apresentaremos os sítios arqueológicos estudados; em seguida a metodologia empregada nas escavações e análises será descrita, e abordaremos os resultados das análises por sítio e suas respectivas urnas. Por fim, o cruzamento das informações com a literatura existente nos oferece algumas possibilidades de interpretações sobre as práticas funerárias locais.

\section{OS SÍTIOS ARQUEOLÓGICOS ESTUDADOS}

\section{SÍTIO BOM JESUS DO BARÉ}

Bom Jesus do Baré (Figura 2) é um sítio a céu aberto identificado em 2001, que teve suas dimensões estimadas e seus vestígios cerâmicos contabilizados através do levantamento arqueológico de caráter nãointerventivo realizado em torno do Lago Amanã (Costa 2011). Na ocasião foram registradas 54 urnas expostas na superfície. Em 2009 o sítio sofreu intervenções de subsuperficie para a avaliação do pacote arqueológico, no qual não se observou a existência de terra preta ou terra mulata. Uma baixa densidade de material cerâmico foi encontrada na área total do sítio, de aproximadamente $7.600 \mathrm{~m}^{2}$ (0,76 ha).

De modo geral, o sítio é constituído por vasos inteiros, ou aparentemente inteiros, que apresentam suas bordas aflorando na superfície. Dessa maneira, levantou-se a hipótese de ser um sítio-cemitério, já que a composição do mesmo se restringia basicamente a dois conjuntos de urnas. O estado de conservação desses vasilhames é precário devido às atividades diárias dos moradores como limpeza de quintais e criação de animais, aliado a construções, clima e variações sazonais.

Durante o mapeamento, que ocorreu no pico da seca, foram estimados os níveis máximo e mínimo da água do lago de acordo com as marcas d'água nas paredes das casas da comunidade. Conforme Costa (2011:37), a ausência de terra preta no sítio pode ser interpretada como conseqüência de imperativos ambien- 


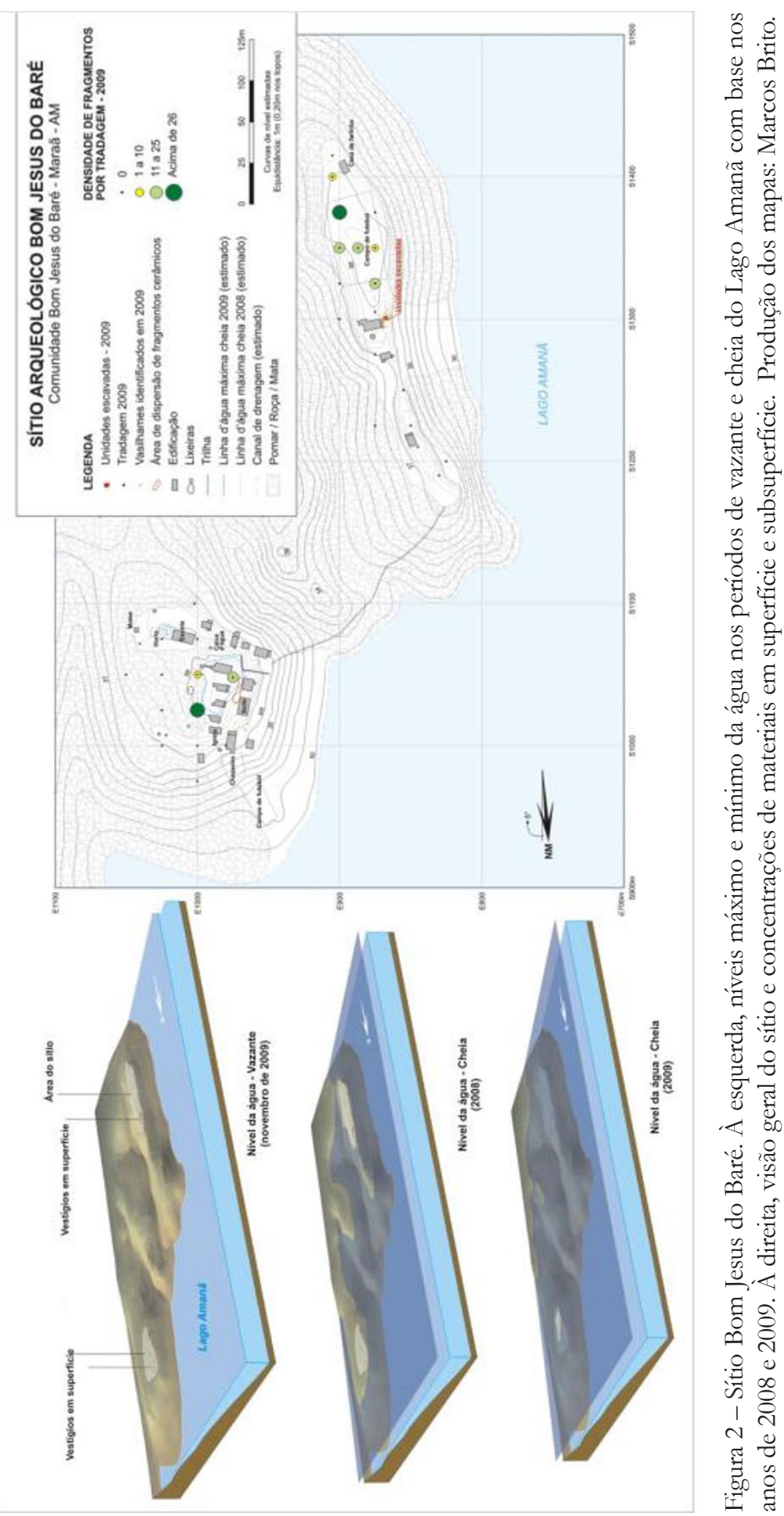


tais e sociais. Por um lado, a variação no nível da água entre as estações de cheia e seca pode ter impedido ou dificultado o processo de produção de terra preta, que é lento e dependente de condições específicas (Schmidt 2010a; 2010b). Por outro lado, o local pode ter sido utilizado com finalidades diferentes daqueles contextos em que se observa a produção de terra preta, como áreas de habitação com fogueiras, lixeiras e latrinas (ArroyoKalin 2010; Castro 2009; Erickson 2003; Schmidt 2010a).

Próximo a uma casa, na porção sul do sítio, foi aberta uma área de escavação de $4 \mathrm{~m}^{2}$, onde foram coletadas quatro urnas, duas delas desmontadas durante os procedimentos de escavação (PN 517 e 518) e as outras duas coletadas com sedimento visando tratamento posterior (PN 516 e 520); outras cinco urnas foram evidenciadas nos limites da área escavada, mas não puderam ser coletadas naquele momento (Figura 2).

A urna PN 517 possuía formato globular e restrição das bordas, o diâmetro do seu bojo era de aproximadamente 60 $\mathrm{cm}$ e de sua borda $40 \mathrm{~cm}$; durante sua escavação em campo foi coletado um vaso no seu interior. Já a urna PN 518 se apresentava muito fragmentada e não foi possível determinar sua forma, apenas dimensões aproximadas (diâmetro do bojo $54 \mathrm{~cm}$ e $60 \mathrm{~cm}$ de altura); durante sua escavação encontrou-se outro vaso associado a ela com provável esmagamento por causa de seu enterramento. Abaixo desses vasos, aos $70 \mathrm{~cm}$ de profundidade, começou a ser evidenciada a urna que recebeu o PN 520. Durante o registro de campo, sua forma foi comparada ao tipo "globular de borda introvertida e contorno complexo" da fase Manacapuru (Lima 2008); suas dimensões eram de aproximadamente 90 $\mathrm{cm}$ de altura e seu bojo tinha $80 \mathrm{~cm}$ de diâmetro; a escavação de seu interior não evidenciou vestígios ósseos.

A quarta urna coletada, PN 516, tem menores dimensões (diâmetro do bojo $57 \mathrm{~cm}$ e $43 \mathrm{~cm}$ de altura) com as bordas erodidas. A escavação em laboratório foi feita em níveis artificiais de $5 \mathrm{~cm}$ até ser encontrado um vaso emborcado no seu interior, próximo ao bojo da urna, a aproximadamente $30 \mathrm{~cm}$ de profundidade. Aparentemente esse vaso não servia de tampa, pois estava inteiro dentro da urna. Abaixo desse vaso foram encontrados vestígios ósseos. O solo do interior da urna possuía textura argiloarenosa e coloração entre 10YR6/8 (brownish yellow) e 10YR6/1 (gray).

\section{SÍTIO SÃO MIGUEL DO CACAU}

O sítio São Miguel do Cacau (Figura 3) localiza-se no Igarapé Cacau, que deságua na porção inferior do Lago Amanã. Foi identificado em 2008 e teve suas dimensões estimadas em $1000 \mathrm{~m}^{2}$, quando duas urnas foram registradas. Em 2011, etapas de mapeamento e escavação foram realizadas, com a abertura de duas unidades consecutivas de $1 \mathrm{~m}^{2}$. Na área foram encontradas uma feição $(\mathrm{F} 1)^{8}$ e duas urnas que receberam os PNs 572 e 573. Tais urnas receberam tratamento de curadoria e escavação em laboratório.

A estratigrafia registrada no local consistiu em três camadas (Figura 3): I) Camada arqueologicamente estéril, 
latossolo argiloso 10YR 6/8 (brownish yellow), $60 / 70 \mathrm{~cm}$ abaixo da superfície; II) Camada adjacente à uma feição, grande concentração de cerâmica, carvões e radículas, solo argilo-arenoso $10 \mathrm{YR} 3 / 3$ (dark brown), de 10 a 30cm de espessura; III) Camada arqueológica com menor ocorrência de cerâmica e carvões, solo argilo-arenoso 10YR 4/3 (brown), com aproximadamente $20 \mathrm{~cm}$ de espessura.

Uma terceira urna - que começou a ser retirada pelos moradores - recebeu o PN 685 e foi desmontada em campo. O recipiente estava localizado na porção oeste do sítio, em uma área sem presença de TPI, ao redor das moradias atuais.

O sítio São Miguel tem sido tratado como um sítio multicomponencial, apesar das incipientes análises cerâmicas e ausência de datações. A hipótese trabalhada é de que a camada cultural mais antiga está associada à fase Caiambé da Tradição Borda Incisa. A camada cultural mais superficial seria formada por cerâmicas da fase Tefé ou com influências da Tradição Polícroma da Amazônia. A estratigrafia amostrada nesta etapa de campo dificulta interpretações mais consistentes, principalmente pelas antigas intervenções para a deposição das urnas.

\section{METODOLOGIA}

Os trabalhos de campo e de laboratório foram desenvolvidos com apoio institucional e logístico do Instituto de Desenvolvimento Sustentável Mamirauá (IDSM) que mantém um Laboratório de Arqueologia em sua sede em Tefé e bases de pesquisa nas RDS Mamirauá e Amanã. Atualmente, dos 32 sítios en- contrados seis passaram por etapas de intervenção: Boa Esperança, Bom Jesus do Baré, Cacoal do Amanã, Monte Sinai, Kalafate e São Miguel do Cacau.

A metodologia usada em campo é semelhante àquela do Projeto Amazônia Central (Castro 2009; Costa 2009; Moraes 2006; Neves 2000, 2010; Neves et al. 2003a). A partir de um "grid" ou quadriculamento fixo, é realizado um levantamento topográfico e de subsuperfície. As primeiras etapas de escavação, por níveis artificiais, são realizadas com o objetivo de coletar amostras para a elaboração de uma cronologia básica de ocupação dos sítios. Além disso, é realizado o resgate de urnas, normalmente orientado pelas demandas dos moradores que indicam os vasos que se encontram em situação de risco.

$\mathrm{Na}$ reserva técnica do Laboratório de Arqueologia do IDSM estão armazenadas as urnas coletadas. A maior parte delas foi escavada em campo, enquanto que outras foram coletadas com todo o sedimento a fim de manter um contexto fechado e controlado (Duday 2005) para posteriormente serem trabalhadas em laboratório sob vários prismas, incluindo a análise de material ósseo e o estudo tecno-estilístico da cerâmica. Neste trabalho nos concentramos em quatro urnas coletadas nos sítios Bom Jesus do Baré e São Miguel do Cacau (Figuras 3 e 4).

A partir do conceito de arqueologia da morte 9 (Duday 2005), também conhecido como "anthropologie de terrain" (antropologia de terreno), os sepultamentos - e tudo que está a eles relacionado - são "lidos" com o objetivo de compreender o contexto e a evolução 


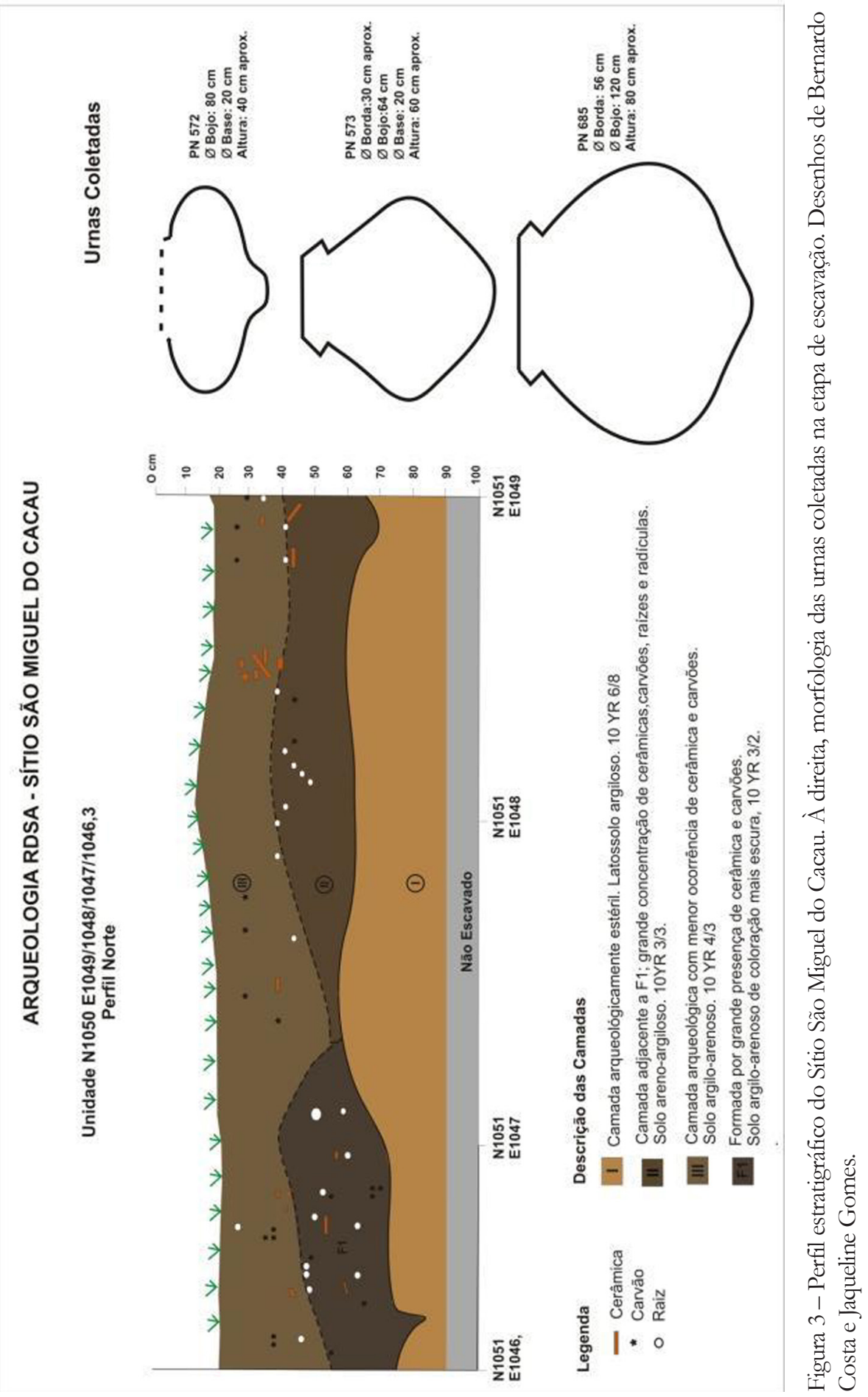


dos diversos processos tafonômicos. Esse conceito vem sendo adaptado ao contexto amazônico, onde os solos são normalmente ácidos, argilosos, com fauna e flora totalmente diferentes dos contextos europeus, para os quais o conceito foi originalmente elaborado, alterando assim os processos de deterioração e de conservação (Mendonça de Souza 2010; Rapp Py-Daniel 2010).

A escavação no interior das urnas priorizou os elementos ósseos como definidores das camadas a serem retiradas. Para realizar a desmontagem das camadas de vestígios ósseos efetuou-se registro fotográfico e um croqui com os elementos ósseos visíveis. Quando possível procedia-se durante a desmontagem à identificação do elemento ósseo, sua face de aparecimento (lateral, frontal, superior, etc.) e o relacionamento com os outros ossos (proximidades anatômicas, articulações). Todas essas informações foram recolhidas para identificar os gestos e os processos de sedimentação ou remeximento (Rapp Py-Daniel 2010).

A identificação dos gestos ligados ao contexto funerário e da posição original dos ossos do esqueleto se fez por eliminação, ou seja, primeiro os processos naturais foram avaliados para em seguida propor possíveis gestos, que por sua vez são a materialização de práticas e rituais. Como todos os ossos encontrados estavam extremamente frágeis, para análise e tomada de medidas durante e após a escavação foi essencial a aplicação de um consolidante acrílico.

No caso da análise tecno-estilística da cerâmica, foi realizada com a mesma metodologia da análise dos fragmentos amostrados nas unidades de escavação, que consiste na aplicação de uma ficha desenvolvida pelo Projeto Amazônia Central e adaptada ao material da região, que contempla toda a cadeia produtiva: matéria-prima, queima, variáveis métricas e formais, além de evidências de utilização (Machado 2005; Moraes 2006; Lima 2008). O sistema de classificação morfológica é o mesmo utilizado por Lima (2008) adaptado para o material da Amazônia Central a partir da proposta de Shepard (1956).

\section{ANÁLISES E RESULTADOS}

\section{BOM JESUS DO BARÉ}

A urna PN 516 (Figura 4) do sítio Bom Jesus do Baré foi a única que continha elementos ósseos preservados, passíveis de uma análise mais detalhada e por isso pôde ser estudada com maior profundidade. Os primeiros ossos a serem identificados foram o crânio e um osso longo, provavelmente tíbia. Alguns outros fragmentos ósseos saíram antes, mas sem uma localização precisa. A base do crânio estava a $32 \mathrm{~cm}$ de profundidade em relação à borda quebrada da urna (aprox. $10 \mathrm{~cm}$ da base). Logo abaixo e ao redor do crânio e da possível tíbia foram encontrados vários outros elementos ósseos (Figura 4). A identificação do material foi muito limitada em função do estado avançado de deterioração dos ossos, cuja a maior parte só estava mantida pelo sedimento; sem ele não haveria como os elementos se manterem estruturados. 


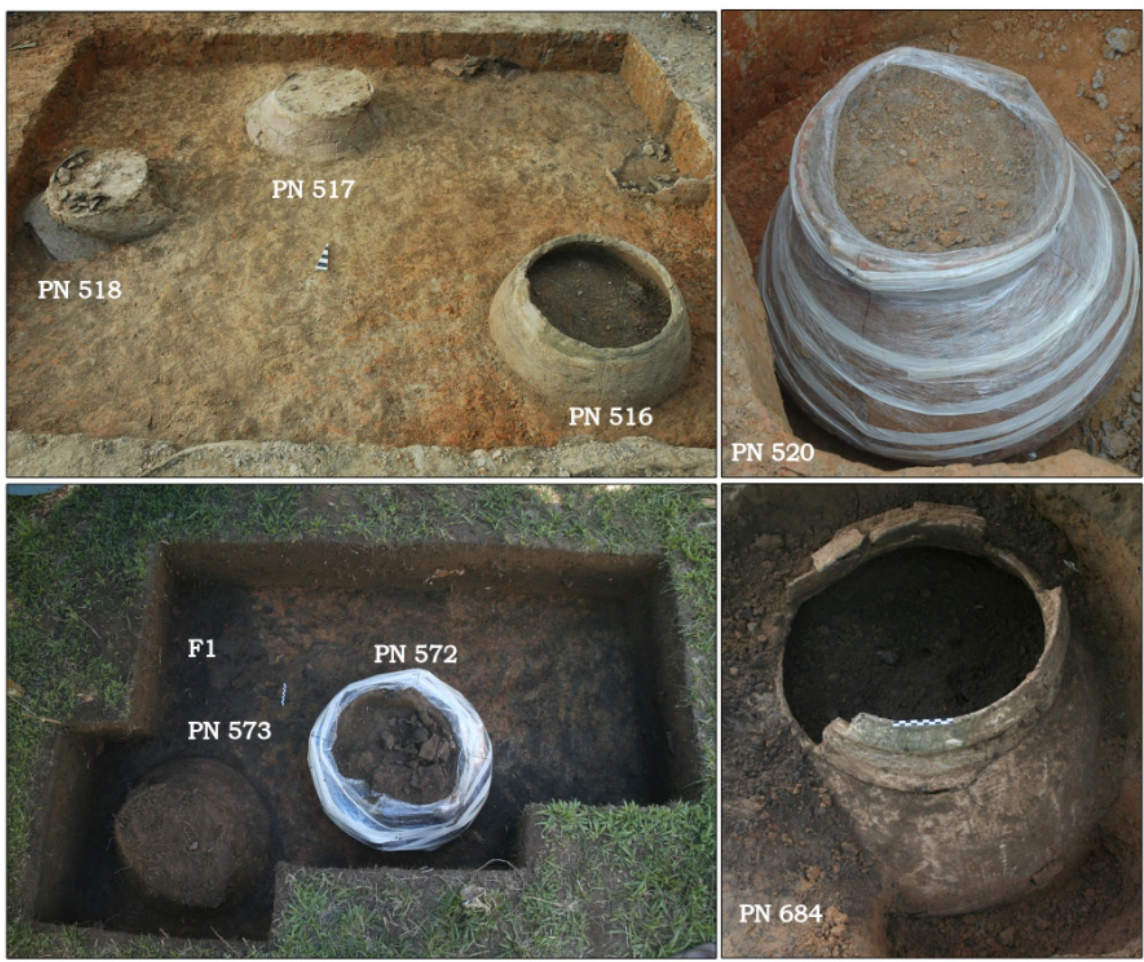

Figura 4 - Urnas in situ. Acima: início da escavação da área de $4 \mathrm{~m}^{2}$ no Sítio Bom Jesus do Baré em 2009; ao lado urna PN 520 encontrada abaixo da urna PN 518. Abaixo: Urnas do Sítio São Miguel do Cacau durante escavação na unidade na base do nível 50-60 cm. Observar a proximidade entre a F1 e as urnas PN 573 e PN 572; ao lado urna PN 685 depois de iniciada a escavação pelos moradores. Fotos de Bernardo Costa e Jaqueline Gomes.

Vários pequenos carvões foram identificados no sedimento, mas não há sinal perceptível de queima sobre os ossos, nem de sedimento queimado no interior do vaso. Todo o sedimento era muito claro, algumas manchas mais alaranjadas eram perceptíveis, onde se constatou a presença de ossos em decomposição. Ao realizar a escavação foi separada uma amostra de sedimento para possíveis análises. Apesar do uso de consolidante, pouquíssimos ossos saíram inteiros. Visto que durante a escavação era possível verificar que os ossos não estavam inteiros e que praticamente nenhum conjunto de medidas osteométricas seria possível, optou-se por não "plastificar" os elementos ósseos, mas somente estabilizá-los por tempo suficiente para terminar a escavação e tentar identificar gestos ou processos tafonômicos. O sedimento dentro da urna era muito argiloso e deve ter auxiliado a desacelerar o processo de decomposição dos ossos, sendo esse efeito criado em função da coesão da argila, de sua capacidade de "encapsular" os elementos e reduzir o oxigênio 
disponível (Rapp Py-Daniel 2010).

Os ossos identificados levam a crer que só havia um indivíduo dentro dessa urna, um adulto muito pequeno e grácil; não há ossos coxais preservados para estimar o sexo do indivíduo. Porém, possivelmente estamos diante de um indivíduo do sexo feminino, visto o tamanho e a forma da mandíbula, as inserções musculares pouco proeminentes e a gracilidade dos ossos longos. Afirma-se que o indivíduo é adulto (mais de 18 anos) em função da mandíbula (Figura 5), onde, apesar do estado de deterioração, com os dentes decompostos ou se decompondo, foi possível verificar que os terceiros molares inferiores já haviam erupcionado e que o alvéolo do segundo molar direito sofreu processo de reabsorção óssea, após queda. Diáfises de ossos longos grandes e pequenos foram encontradas no interior do vaso, mas as epífises não estavam preservadas para verificarmos os processos de ossificação.

Inicialmente não tinha sido identificada coerência ou proximidade anatômica entre os ossos. Entretanto, no decorrer da escavação, percebemos concentrações e posições ósseas anômalas a um sepultamento secundário "clássico" (feixes de ossos longos, ausência de ossos pequenos, ossos em posição horizontal ou apoiados contra o bojo), abrindo a possibilidade de estarmos diante de um sepultamento primário inteiro ou enterramento de um corpo parcialmente desarticulado, mas com os ossos ainda envolvidos pelas partes moles. As concentrações ósseas mais significativas verificadas foram: i) Algumas costelas estão concentradas em uma mesma porção no interior da urna, normalmente paralelas umas às outras, infelizmente visto o grau de deterioração não foi possível identificar a que lado, esquerdo ou direito, elas pertenciam.

ii) As fíbulas também estão paralelas, além disso, a posição da possível tíbia indica uma proximidade anatômica significativa.

iii) Há diáfises de ossos longos pequenos, mão ou pé, associadas e verticalizadas, em dois grupos distintos, no interior da urna. Não foi encontrado nenhum elemento que pudesse explicar um efeito de parede no interior da urna, longe das paredes do vaso, que pudesse explicar a verticalização das diáfises.

Pensamos que um preenchimento rápido do vaso por terra, enquanto ainda havia partes moles preservadas, pode explicar essa situação. Infelizmente, não foi possível identificar os gestos de tratamento do morto prévios ao enterramento, mas as perspectivas são muito interessantes e abrem novas possibilidades que diferem do modelo divulgado, onde urnas e sepultamentos secundários são quase sempre positivamente correlacionados, apesar de relatos de sepultamentos primários dentro de urnas da fase Marajoara (Meggers \& Evans 1957; Schaan 2004) e também em urnas Tupiguarani, tal como discutido recentemente por Müller \& Souza (2011). Como bem demonstram Müller \& Souza (2011) é comum interpretações de enterros em urnas como sendo secundários, resultado de observações incompletas e de escavações rápidas. Grande movimentação dos ossos é esperada em sepultamentos primários, principalmente se os mesmos estão dentro de urnas - a decomposição em espaços vazios gera um aspecto de desor- 
dem, mas que muitas vezes pode ser identificado através do posicionamento dos ossos. O contexto dentro da urna fala a favor de um preenchimento natural por terra, aparentemente não antrópico, mas uma análise de solos é necessária para compará-la ao sedimento geológico ao redor. Como mencionado anteriormente, a falta de material ou formação de TPI pode ser o resultado de alagamentos repetidos, que perturbariam e removeriam a terra e o material deixado sobre o solo, ou de um tipo de atividade diferenciada que não formaria TPI como um contexto exclusivo de cemitério.

Áreas de TPI que atualmente são ocupadas por comunidades na região frequentemente têm a camada antropogênica reduzida por atividades de limpeza e erosão natural do solo. Se associarmos a essas constatações a pro-

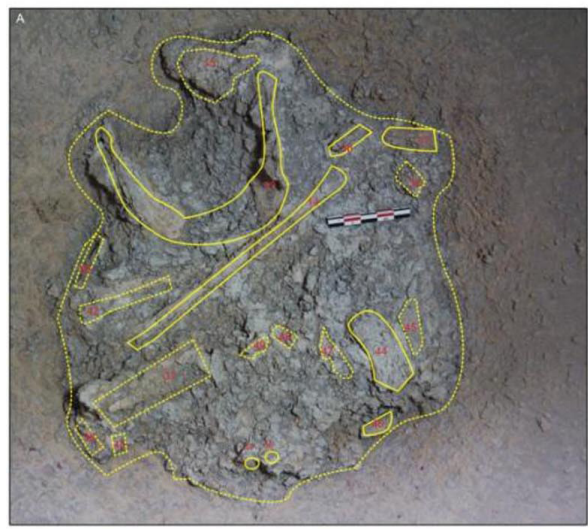

pensão a alagamento nesse sítio, entendemos, talvez, a razão da falta de TPI e o pouco material associado. Ao mesmo tempo o sedimento não deve ser muito ácido, pois ainda havia ossos visíveis.

Esses fatores também são relevantes para a análise cerâmica, visto que a superfície interna da urna, ainda bem preservada, apresenta polimento, enquanto a superfície externa está muito deteriorada $^{10}$. A pasta apresenta alto grau de fragilidade, que pode estar relacionada às intempéries naturais. Foram observados como antiplásticos grande quantidade de espículas de cauixi e partículas de caraipé, além de carvões e minerais como hematita e grãos de quartzo. A técnica da manufatura utilizada foi o acordelamento nas paredes; na porção superior da urna foram observadas aplicações de placas de argila. Assim, mais de uma técnica foi utiliza-
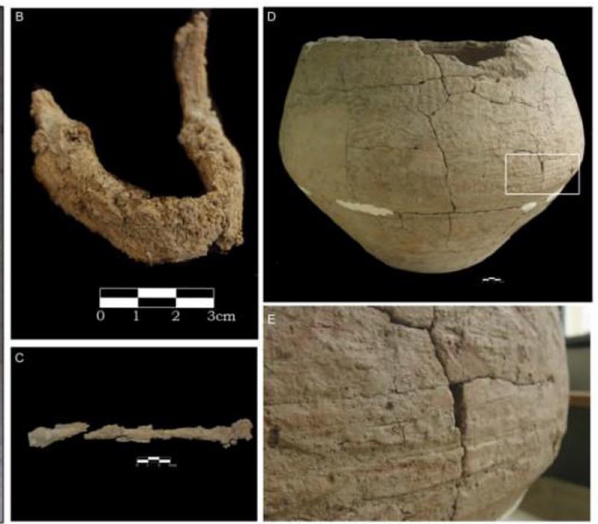

Figura 5 - A) Registro fotográfico e croqui digital da $3^{a}$ etapa de escavação do interior da urna PN 516. B) Mandíbula já consolidada, na qual foi possível verificar que os terceiros molares inferiores já haviam erupcionado e que o alvéolo do segundo molar direito sofreu processo de reabsorção óssea, após queda. C) Fíbula identificada próxima à base da urna. D) Urna após procedimentos de restauração para estabilização da peça. E) Detalhe de uma das áreas que ainda possui decoração: incisões duplas e retilíneas. Fotos: Anne Rapp PyDaniel e Jaqueline Gomes. 
da resultando em paredes que variam muito em espessura: na porção inferior do vaso as paredes possuem aproximadamente $2 \mathrm{~cm}$ enquanto próximo a borda ultrapassam 3,5 cm de espessura. Essa característica possivelmente afetou a queima da peça, pois seus fragmentos apresentaram diferentes indícios de processos de queima, como colorações mais claras no interior da pasta dos pedaços próximos à base e variações de tons de cinza e preto no restante da peça.

Nos aspectos formais, a urna apresenta contorno simples, mas pela ausência da borda não se pode dizer que esta era sua forma original. É interessante notar a presença de sulcos em baixo-relevo que formam motivos quadrangulares, mas que não foram passíveis de decalque, tampouco determinar se a técnica plástica utilizada era acanalada ou incisa.

A urna apresenta a seguinte estrutura decorativa: a área próxima à provável borda é delimitada por uma linha que apresenta ondulações; na área que compreende o pescoço há motivos com padrões retilíneos e quadrangulares; o bojo é delimitado por incisões duplas seguidas por uma linha ondulada; na área abaixo do bojo até a base foram observados através de lupa vestígios de engobo branco e pintura vermelha.

\section{SÃO MIGUEL DO CACAU}

As três urnas do Sítio São Miguel do Cacau que serão apresentadas aqui foram escavadas em campo (Urna PN 685) e em laboratório (Urnas PN 572 e PN 573). No início da escavação da urna PN 573 o solo era de textura argi- lo-arenosa, com a coloração 10YR5/4 (yellowish brown), sendo visíveis várias radículas. Na altura do bojo o solo tornouse mais escuro e menos compactado, sendo observadas raízes menores e bioturbações, assim como moderada quantidade de fragmentos cerâmicos no sedimento. Foram coletados vários fragmentos de bases de assadores dispostos verticalmente, e posteriormente observada presença de solo acinzentado, de carvões e de pequenas bolotas de argila, além de um pequeno fragmento ósseo coletado na peneira.

Conforme a escavação se aproximava da base, tornaram-se mais frequentes os vestígios ósseos, sendo coletado um fragmento de osso longo; na base da urna foram identificados vestígios ósseos junto a um pequeno vasilhame (com $8 \mathrm{~cm}$ de diâmetro), cuja decoração consiste em uma faixa de finas incisões curtas diagonais e paralelas. Próximo ao pequeno vaso havia um solo mais úmido de coloração mais escura, além de muitos carvões, mas o sedimento não parecia queimado. No fundo da urna também foi verificado um sedimento mais claro (7.5YR 7/1 light gray).

A desmontagem da urna seguiu, na medida do possível, as partes diagnósticas (bojo, colo, etc.) e após procedimentos de limpeza foram observados vestígios de pintura vermelha sobre engobo branco na porção inferior ao bojo. O bojo é decorado com incisões duplas retilíneas que formam motivos quadrangulares, enquanto que na porção superior da urna, em superfície já bastante desgastada, identificamos, através da lupa, vestígios de pintura e engobo em alguns frag- 
mentos. Na pasta foi observada presença abundante de cauixi e minerais (hematita e pequenos grãos de quartzo) e a queima mostrou-se bastante regular e completa. A espessura das paredes varia entre 1,5 e $2 \mathrm{~cm}$, o contorno da peça é complexo, possuindo borda introvertida. No interior do vaso foi encontrado um grande fragmento de assador, além de vários fragmentos basicamente sem decoração que não ultrapassam $6 \mathrm{~cm}$ de comprimento. De todo o material, apenas uma borda é diagnóstica, com extroversão tipo flange e lábio serrilhado com decoração típica da fase Caiambé (Figura 6).

O material ósseo identificado dentro dessa urna pertence a pelo menos um (01) indivíduo; o estado de conservação é péssimo, mas algumas partes do osso cortical e do osso esponjoso ${ }^{11}$ estão preservadas (Figura 6). O processo de deterioração é muito intenso limitando as identificações e as estimativas de sexo e idade. As poucas extremidades identificadas parecem ossificadas, apontando para uma idade adulta ou adolescente, porém o tamanho dos ossos é muito pequeno (por exemplo, o diâmetro da extremidade distal da diáfise do rádio esquerdo tem aproximadamente $1,5 \mathrm{~cm})$. Não foi possível identificar traços de queima sobre os ossos (análise macroscópica). Também não é possível saber se os ossos estavam dispostos com alguma lógica de organização ou se havia coerência anatômica, mas é interessante notar que há ossos pequenos presentes (extremidade distal de falange proximal) e que num pequeno bloco (PN 573.53) havia ao menos três costelas associadas. O crânio estava no fundo do vaso, todos os ossos estavam por cima ou ao lado. O vaso tem $60 \mathrm{~cm}$ de diâmetro; esse tamanho permite vislumbrar a presença de um indivíduo pequeno articulado ou desarticulado no seu interior.

Os fragmentos de assador encontrados no interior da urna estavam aproximadamente na porção mesial da mesma e a maior parte dos pequenos fragmentos de cerâmica encontrados no seu interior estava acima do assador. Uma interpretação cabível é que este grande fragmento de assador foi utilizado como tampa; sua quebra teria permitido o preenchimento do espaço vazio por sedimento e pequenos fragmentos cerâmicos que estavam no solo.

A urna PN 572 (Figura 7) possui menores dimensões e morfologia diferenciada, apresentando baixa altura $(40 \mathrm{~cm})$ e um largo bojo (diâmetro de $80 \mathrm{~cm}$ ) que é posteriormente afilado formando uma base côncava (Figura 3). A pasta cerâmica apresenta caraipé como principal antiplástico, a queima é irregular, apresentando em algumas áreas oxidação, mas de modo geral é redutora. A decoração consiste em engobo vermelho, não sendo identificada outra camada de pintura.

Desde a escavação in situ o recipiente já se apresentava bastante fragmentado; desta forma, procedeu-se durante a escavação também à sua desmontagem. Em seu interior foi encontrada grande quantidade de material cerâmico. O sedimento apresentou coloração 10YR 3/2 (very dark grayish brown), textura areno-argilosa com pouca compactação, com bioturbações formadas por radículas e raízes de espessura fina. Constatou-se também pequenos carvões dispostos de maneira esparsa 
na parte superior. Do sedimento peneirado foram coletados fragmentos de cerâmica e bolotas de argila. Em alguns pontos o sedimento, apesar de pouco compacto, apresentou concreções bem escuras; além disso, fragmentos cerâmicos estavam próximos a uma maior concentração de carvões.

Uma estatueta chocalho (Figura 7D) foi evidenciada a aproximadamente $5 \mathrm{~cm}$ abaixo da borda, apresentando traços femininos com representação de seios e genital na sua porção frontal. Na superfície dorsal do artefato há uma representação em relevo de uma coluna vertebral (ou possivelmente uma trança); ali também foram identificados vestígios de engobo branco. A estatueta possui marcas de quebra no local da cabeça, seus membros inferiores e as nádegas lembram alguns quadrúpedes. Chegando próximo à base foram evidenciados fragmentos de um pequeno prato não decorado com quebras recentes e antigas, indicando um esmagamento anterior à escavação.

Apenas durante o peneiramento foram coletados fragmentos ósseos. Pela análise macroscópica não foram identificados vestígios de processos de queima. Visto a péssima conservação dos ossos não foi possível determinar a idade com precisão, mas os fragmentos de costelas identificados sugerem tratarse de um indivíduo infantil, tanto pelo tamanho quanto pela morfologia.

Por último, a urna, ou vasilhame, PN 685 (Figura 8) foi toda escavada em campo, não sendo identificado vestí-
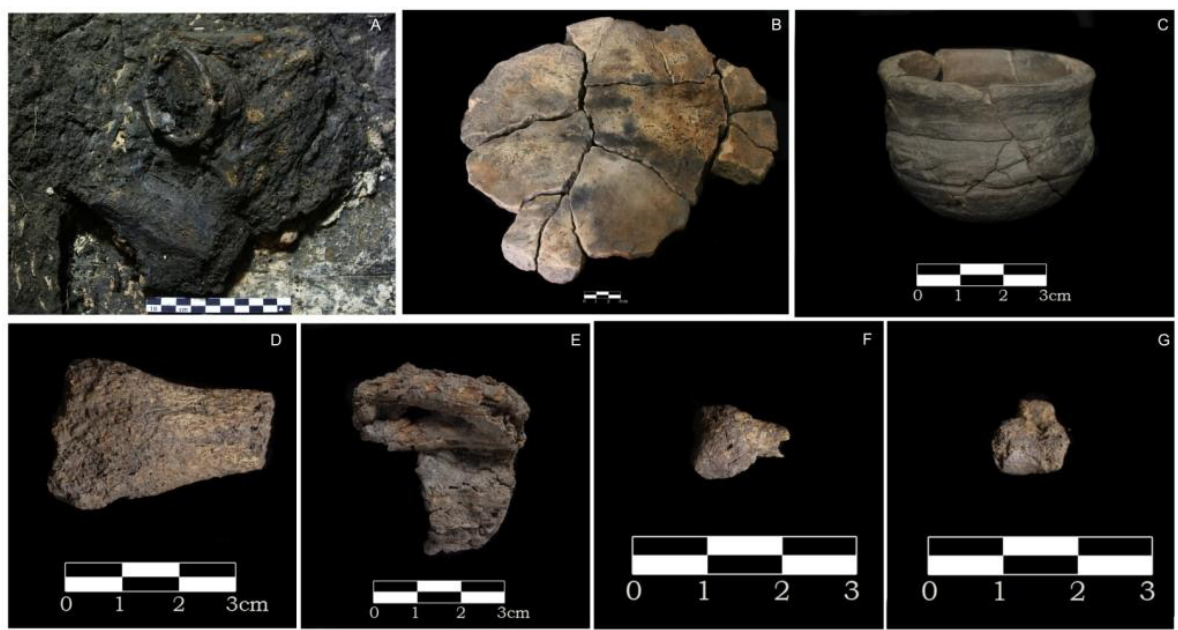

Figura 6 - A) Concentração de vestígios ósseos ao redor do pequeno vasilhame cerâmico evidenciados na base da urna e retirados em bloco. B) Assador parcialmente remontável que estava na altura do bojo da urna. C) O pequeno vasilhame já restaurado. D) Extremidade distal da diáfise do rádio esquerdo. E) Três costelas associadas observadas durante a escavação do bloco (PN 573.53). F) Extremidade distal de falange proximal - face dorsal. G) Extremidade distal de falange proximal - face fronto-distal. Fotos: Anne Rapp PyDaniel e Jaqueline Gomes. 
gio de material ósseo em seu interior. Observações em campo apontaram para semelhanças entre o interior do vaso e a feição encontrada na unidade de escavação, principalmente no que se refere à composição interna (bolotas de argila, terra preta, semente queimada e cerâmicas). O material cerâmico proveniente de seu interior consiste em 330 fragmentos, sendo 38\% deles decorados e de dimensões variáveis, alguns maiores de $15 \mathrm{~cm}$; após uma curadoria inicial também verificou-se que vários elementos são parcialmente remontáveis (Figura 8).

Alguns fatores chamam atenção para esse vaso:

i) Sua localização em provável complexo funerário na porção oeste do sítio e a proximidade de várias outras urnas.

ii) A enorme quantidade de material cerâmico coletado em seu interior, principalmente o alto número de peças decoradas e tamanhos dos fragmentos.

iii) A constante presença de TPI em todo interior do vaso enquanto que o solo ao seu redor é argiloso, compacto e de coloração alaranjada.

iv) A ausência de material ósseo humano.

\section{DISCUSSÃO}

Apesar das particularidades observadas em cada urna e em cada sítio, alguns padrões podem ser encontrados; essas recorrências referem-se tanto ao tipo de enterramento, quanto ao contexto funerário como um todo.

O sítio Bom Jesus do Baré (Figura 2) se mostrou extremamente fértil sobre a or- ganização de contexto funerário. É interessante notar a quantidade de vasilhames que foram evidenciados em $4 \mathrm{~m}^{2}$ de área escavada - ao todo nove urnas, duas delas com vasos em seu interior, além de uma provável urna esmagada entre as urnas PN 518 e PN 520, que só poderá ser confirmado com os procedimentos de restauração. A sobreposição das urnas com intervenções para enterramentos, que alcançaram $157 \mathrm{~cm}$ de profundidade, sugere, no mínimo, intensas atividades na área, que parece ter sido usada exclusivamente para o enterramento de urnas com presença de possível sepultamento primário no interior.

No Sítio São Miguel é notável a grande quantidade de material cerâmico dentro das urnas. Nos dois primeiros casos mencionados (PN 572 e 573) os fragmentos não pertencem à própria urna, mas também não parecem ter sido colocados. Desde as suas bordas encontramse materiais de pequenas dimensões que provavelmente estavam presentes no sedimento quando este preencheu o interior dos vasos enterrados na mancha de terra preta localizada na porção leste do sítio. Na urna PN 572, que desde a escavação in situ já se apresentava bastante fragmentada, observamos maior quantidade de material cerâmico externo, enquanto que na urna 573 o material cerâmico foi mais frequente apenas acima do assador. No caso da urna PN 685 os fragmentos são grandes e diagnósticos, muitos deles decorados, o que leva a crer que a deposição deles no seu interior foi intencional.

É interessante notar que nos três vasos foi recorrente encontrar fragmentos re- 

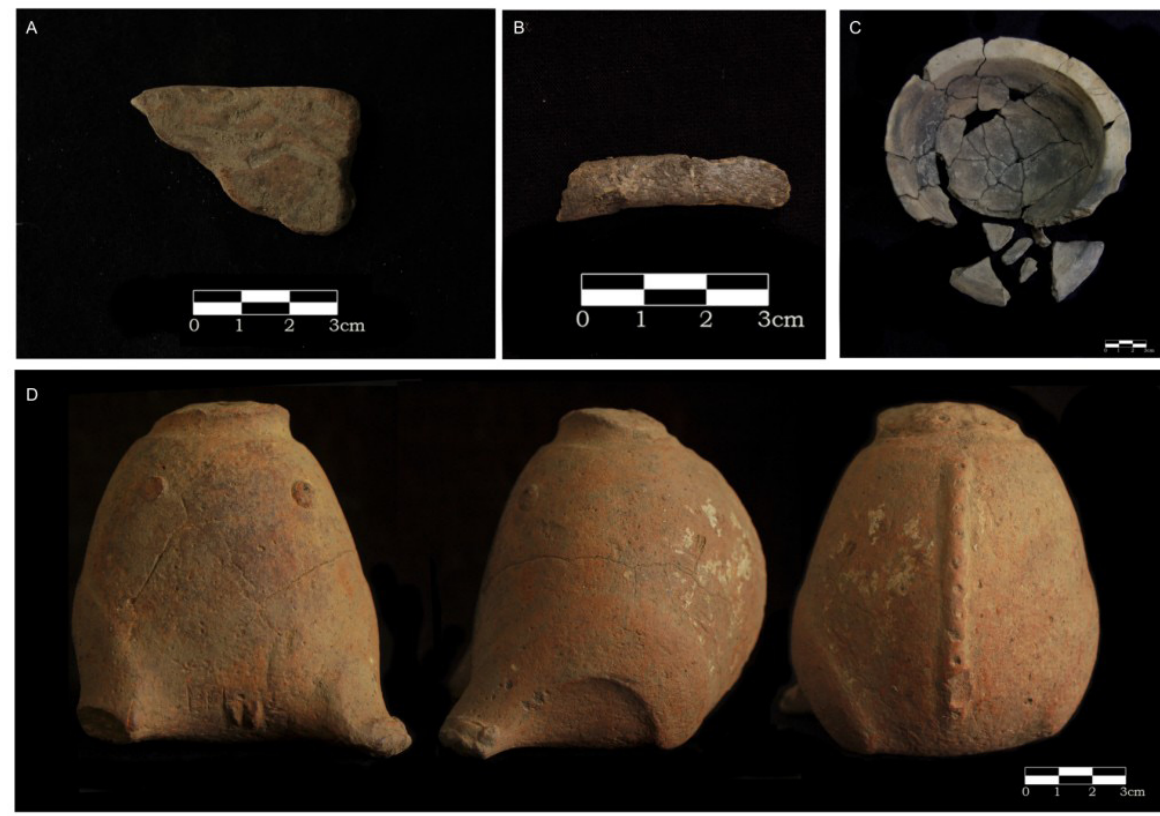

Figura 7 - A) Borda extrovertida com decoração incisa com motivo recorrente da fase Caiambé. B) Fragmento de costela. C) Vasilhame encontrado na base da urna e parcialmente remontado. D) Estatueta chocalho encontrada próximo à borda da urna. Fotos: Anne Rapp Py-Daniel e Jaqueline Gomes.

montáveis de assadores, mas somente na urna PN 573, do Sítio São Miguel do Cacau, o fragmento parece ter sido grande o suficiente para servir de tampa. Esta teve o maior número de ossos preservados; entretanto, das urnas escavadas na região com presença de ossos, essa era a que tinha o solo mais claro, sugerindo menor processo de modificação antrópica.

Na urna PN 572 do Sítio São Miguel do Cacau, além de um prato encontrado em sua base, há uma estatueta chocalho que pode conferir um caráter especial àquele contexto. A estatueta conjuga características zoomórficas e antropomórficas, apresentando marcas de quebra na porção superior onde estaria a cabeça (Figura 7).
$\mathrm{Na}$ cosmologia ameríndia os artefatos se encontram profundamente ligados a noções de corpo e corporalidade, que apenas agora começam a ser exploradas pela arqueologia (Barreto 2011a). Barreto, em seu levantamento inicial sobre a representação do corpo nas sociedades ameríndias pré-coloniais, destaca que a quebra das cabeças é um padrão recorrente observado em diversos locais da Amazônia, como a região de Santarém e a ilha de Marajó (Barreto, 2011 b; Schaan 2001). De outro modo, a presença de artefatos no interior de urnas funerárias é geralmente associada a referências de pertencimentos sociais e status dos indivíduos enterrados, por exemplo, as tangas dentro das urnas Marajoara, ilha de Marajó (Schaan 

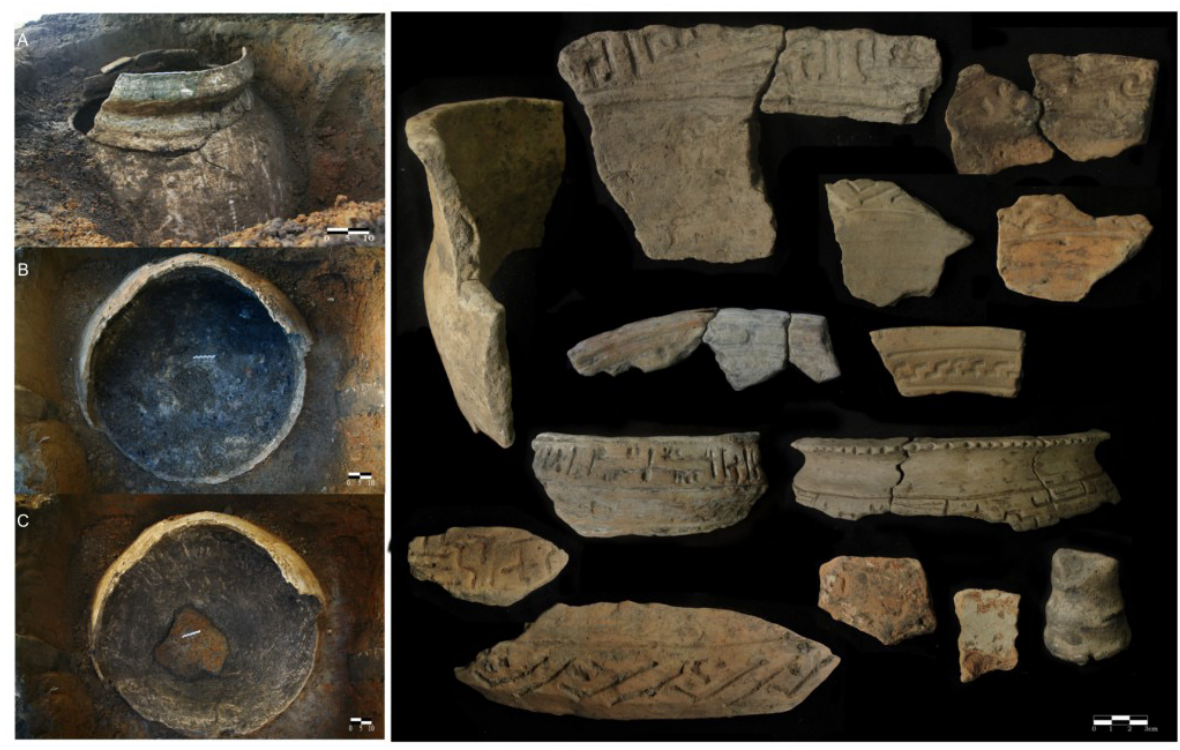

Figura 8 - À esquerda: A) Urna PN 685 após intervenção dos moradores; B) Urna durante escavação controlada, observar coloração escura do solo; C) Final da escavação urna com um fragmento de assador na base. À direita cerâmicas provenientes do interior da urna que podem ser relacionadas à fase Caiambé. Fotos: Jaqueline Gomes.

2003), e a presença de miçangas dentro - e na composição - das urnas Maracá (Guapindaia \& Machado. 1997). Levando em consideração as dimensões (bojo com $80 \mathrm{~cm}$ de diâmetro e altura de 40 $\mathrm{cm}$ ) e a ausência de informações no que se refere à coerência anatômica ou de organização do material ósseo infantil identificado, não é possível inferir que se tratava de um sepultamento primário ou se somente os ossos foram sepultados, mas a forma peculiar do vaso e o conteúdo conferem a todo o conjunto um caráter diferenciado, podendo estar relacionado com a idade - jovem - do indivíduo e/ou sua família e grupo.

$\mathrm{Na}$ Amazônia Central são recorrentes sepultamentos secundários em urnas relacionadas à Tradição Borda Incisa (Hilbert 1968; Moraes 2006, 2010a), mas há grande variedade de práticas funerárias como sepultamentos primários, secundários, individuais e múltiplos, principalmente associados à fase Paredão entre os séculos VII a XII (Moraes 2006; Rapp Py-Daniel 2010). Mesmo no meio de tanta diversidade é possível encontrar elementos de "continuidade" como é o caso da associação de apliques antropomorfos, as "cabecinhas Paredão" nas urnas e nos sepultamentos diretos (Rapp Py-Daniel 2010). No caso da região do Lago Amanã, sugerimos que a presença de vasos e pratos inteiros dentro das urnas também pode representar uma "continuidade" de gestos e ritos. Porém não é possível fazer interpretações sobre o simbolismo desses gestos.

Esse quadro de grande diversidade parecia não ser estar associado a contex- 
tos funerários da Tradição Polícroma, a ponto de diversos autores definirem sepultamentos secundários em urnas antropomorfas como um traço diagnóstico da tradição (Evans \& Meggers 1968; Lathrap 1970; Brochado 1984). Percebe-se, hoje em dia, no entanto, que há variações na decoração dos tipos de urnas polícromas, visto que nem todas as urnas da Tradição representam formas humanas, por vezes os vasos não possuem características antropomorfas, mas nas decorações geométricas podem ser identificados elementos humanos (Moraes \& Lira 2009; Moraes 2006). Porém a Tradição Polícroma também apresenta particulariadades, principalmente no Baixo Amazonas, onde a mesma apresenta características diferentes da Amazônia Ocidental. Por exemplo, Schaan (2004) apresenta o estudo dos contextos funerários da fase Marajoara, onde percebeu que nos tesos Camutins a presença de sepultamentos primários e secundários dentro da fase variou de acordo com o tempo e que a variação estava provavelmente ligada a uma mudança no próprio ritual funerário. A mudança das práticas nesse caso não está associada a novos padrões de ocupação ou fases, o que sugere cautela em todos os tipos de interpretação sobre contextos funerários.

$\mathrm{Na}$ região do Lago Amanã nenhuma urna encontrada até o presente possui traços antropomorfos ${ }^{12}$. Os aspectos formais das urnas nos sítios Bom Jesus e São Miguel do Cacau, com exceção da urna PN 572, apresentam uma estrutura morfológica bastante parecida. Essa semelhança é reforçada pela estrutura decorativa observada nas peças: presença de linhas incisas delimitando as áreas constituintes da estrutura do vaso (borda, bojo e base); preenchimento da área do bojo por motivos retilíneos e quadrangulares realizados por incisões e acanalados e uso de engobo e pintura na parte inferior do bojo. O uso das técnicas de pintura não exclui a possibilidade de relações com a fase Caiambé que, quando criada por Hilbert, atribuiu, dentre os seis estilos definidos para a fase, um estilo polícromo, frequente em toda a sequência estratigráfica (1968). Aliado a isso, os vestígios cerâmicos encontrados no interior das urnas também indicam relações com a fase Caiambé. Embora os estudos cerâmicos e do contexto desta fase realizados apenas por Hilbert (1962; 1968) nas proximidades da cidade de Tefé sejam incipientes, situamos o contexto de Bom Jesus do Baré e São Miguel do Cacau na segunda metade do primeiro milênio da Era Cristã, apesar da carência de datações absolutas.

Visto a pequena amostragem e as dificuldades de análise dos corpos dos indivíduos falecidos e enterrados nas urnas do Lago Amanã, não se pode chegar a conclusões definitivas. Entretanto, foi observada a presença de elementos ósseos pequenos e proximidades anatômicas que permitem cogitar sobre a presença de uma prática funerária de sepultamentos primários dentro de urnas ainda pouco comum na literatura relativa à arqueologia amazônica.

No que se refere aos sepultamentos secundários dentro de urnas, Barreto (2008) expõe claramente sobre sua 
importância, pois estes demandariam um envolvimento duradouro da comunidade com o morto e estão normalmente associados a pessoas de maior prestígio. Por exemplo, no sítio Hatahara (Neves et al. 2003b; Machado 2005; Rapp Py-Daniel 2010), na Amazônia Central, percebe-se diferenças na composição dos sepultamentos secundários e primários da fase Paredão, podendo traduzir distinções entre gênero e idade. Na região do Lago Amanã ainda não é possível saber se os vasos também tiveram outras funções, implicando um reaproveitamento, ou se eram fabricados exclusivamente para serem urnas, implicando produções especializadas que possivelmente eram preparadas com antecedência, ou se fossem fabricadas especialmente para o indivíduo falecido, o tratamento destinado ao corpo deveria ser longo o suficiente para permitir que o vaso ficasse pronto.

Os processos que levam à deterioração ou conservação de material orgânico são variados e atuam ao mesmo tempo. Visto que os ossos encontrados nessas urnas estavam em processo de decomposição (eventualmente eles iriam sumir), não se deve pensar em processos de preservação em termos absolutos e sim em processos que estavam retardando a velocidade da decomposição. Podemos identificar alguns processos relacionados à deterioração do material ósseo (chuva, raízes e bioturbações), mas acreditamos que principalmente o solo argiloso auxiliou na preservação desses materiais.

Entretanto, é necessário verificar a composição básica da TPI e medir a acidez do sedimento para ver quais são os elementos presentes. Importante também é compreender a presença de carvões e/ou elementos que indicam queima no interior desses recipientes e localizar sua provável origem, se endógena ou exógena, que poderia ter como hipóteses presença de terra preta ao redor ou alguma fogueira nas proximidades.

Como em várias áreas da Amazônia Amazônia Central (Castro 2009), rio Madeira (Moraes 2010b); Santarém (Gomes 2010; Márcio Amaral comunicação pessoal 2010) - no contexto do Lago Amanã há presença de uma feição próxima às urnas 572 e 573, com material cerâmico, bolotas de argila e carvão, que ultrapassa a camada de terra preta até chegar ao latossolo. Frequentemente, essas feições, também conhecidas como bolsões, possuem uma composição artefatual diferenciada, com maior presença de material diagnóstico (Moraes 2006, 2010a; Castro 2009; Guapindaia 2008, Márcio Amaral, comunicação pessoal 2010).

No Sítio São Miguel do Cacau é intrigante a presença de TPI no interior da urna PN 685, que pode ser resultado da formação in situ dentro da própria urna, pois muitos carvões foram observados durante a escavação; ou do preenchimento pela TPI mais superficial que pode ter existido ao seu redor e penetrado no vaso por quebras e fissuras.

No sítio Bom Jesus do Baré, a ausência de TPI e a pouca densidade de material cerâmico fragmentado ao redor das urnas levanta também alguns questionamentos:

1) Haveria áreas destinadas para cemitérios?

ii) A dinâmica da ocupação e dos ciclos hidrológicos não teriam permitido a formação 
e/ou manutenção das áreas de TPI?

A presença de material de acompanhamento dentro dos vasos, a proximidade das urnas nos sítios arqueológicos, aliados à forma e às características das urnas, levam a pensar num alto grau de uniformidade durante a fase Caiambé, que ainda deverá ser melhor explorada através das análises espaciais e cerâmicas.

Esses resultados iniciais demonstram que a região do Lago Amanã pode colaborar para algumas questões importantes sobre práticas funerárias pré-coloniais e sua diversidade de ocorrência no registro arqueológico. Apesar de alguns trabalhos já terem explorado o potencial simbólico e considerado tais práticas como índices de complexidade social - especialmente na fase Marajoara (Barreto 2008, 2010; Chaumeil 1997; Schaan 2003), tais análises quase sempre se concentram no estudo estilístico das urnas, seu contexto de deposição e a espacialidade desses vestígios no sítio arqueológico, sem a descrição dos remanescentes ósseos coletados, principalmente devido aos estados de conservação desses vestígios que em geral se apresentam bastante friáveis.

Em nosso estudo, apesar do péssimo estado de conservação foi possível obter informações importantes durante $\mathrm{O}$ momento de escavação. Embora não seja o objetivo inferir sobre padrões de hierarquização social, os dados nos permitem pensar sobre as relações sociais naquelas sociedades, como no fato do sepultamento infantil sugerir importância da continuidade genealógica, ou, por exemplo, a formação de espaços específicos no sítio para a deposição das urnas que podem ser entendidos como "lugares de memória" e constituição física de paisagens que são também simbólicas.

\section{CONSIDERAÇÕES FINAIS}

Em grande parte das pesquisas, as urnas funerárias são normalmente vistas como um elemento característico, presente ou ausente, auxiliando na determinação de tipologias classificatórias, mas a variedade das práticas funerárias e a variabilidade estilística entre as urnas não são utilizadas na construção das hipóteses de ocupação, tampouco para explicar o desenvolvimento de complexos que não são só cerâmicos (Barreto 2008:97).

Estudos mais aprofundados sobre o material cerâmico estão em andamento e a possibilidades de análises químicas oferecerão resultados mais completos e significativos. Entretanto, os dados apresentados formam um conjunto esquemático no que se refere às práticas funerárias e os períodos cronológicos relacionados às duas grandes tradições cerâmicas na Amazônia Central.

Enquanto a literatura disponível aponta que urnas antropomorfas com vestígios de sepultamentos secundários e cremações estão relacionadas às práticas funerárias encontradas nos sítios da Tradição Polícroma, urnas com vestígios de sepultamentos secundários e enterramentos primários estão relacionadas a alguns contextos mais antigos dos sítios e das fases da tradição Borda Incisa.

No contexto local, a presença de urnas com indivíduos de idades diferentes chama a atenção, pois o tratamento fu- 
nerário semelhante para diferentes faixas etárias pode ser interpretado como de sociedades mais igualitárias ou famílias com estatutos diferenciados, onde o status é herdado e não adquirido. Esse tipo de inferência não pode ser feita de maneira direta, mas como já dizia há décadas Gordon Childe (1929) e posteriormente Henri Duday (2005) o mundo funerário representa, de maneira ainda mais marcada, as relações sociais do mundo dos vivos (Barreto 2008). Os padrões verificados entre os sepultamentos da fase Caiambé são compatíveis com um padrão geral de mudança social verificado nas terras baixas sul-americanas no primeiro milênio de nossa era (Neves 2011a, 2011b). Tais mudanças são caracterizadas pelo estabelecimento disseminado da vida sedentária e, arqueologicamente, por sinais visíveis de transformações paisagísticas.

Este artigo foi elaborado com o intuito de divulgar as pesquisas ainda pouco conhecidas que estão sendo realizadas na região do Lago Amanã. Um tema não explorado nesse momento, pois ainda está em processo de análise, é a disposição das urnas dentro dos sítios. Também será necessário verificar se há sítios, do mesmo período, que são exclusivamente de habitação, pois isso corroboraria a ideia de uma delimitação espacial entre o mundo dos vivos e o mundo dos mortos, onde os mortos seriam enterrados em conjunto, em cemitérios.

\section{AGRADECIMENTOS}

Agradecemos ao Instituto de Desenvolvimento Sustentável Mamirauá, pelo apoio financeiro e físico para a realização das pesquisas, particularmente nas pessoas de $\mathrm{Hel}-$ der Queiroz, Deborah Lima, Nelissa Peralta, Miriam Marmontel e João Valssechi; ao Prof. Claide Moraes pelas sugestões; à Val Moraes pelo restauro das peças; à Marcos Brito pela produção dos mapas do sítio Bom Jesus do Baré. Também somos gratos aos moradores das comunidades que acompanham e apóiam as pesquisas arqueológicas na região.

\section{NOTAS}

${ }^{1} \mathrm{O}$ lago Amanã é principal lago da RDS Amanã, uma unidade de conservação de uso sustentável que possui 2,35 milhões de hectares e abarca terrenos de terra firme e várzea, apresentando alta biodiversidade por se encontrar entre ecossistemas de águas claras (bacia do Solimões) e águas pretas (Bacia do Rio Negro). A RDS Amanã foi criada pelo Estado do Amazonas em 1998 e é gerida pelo Centro Estadual de Unidades de Conservação (CEUC) e pelo Instituto de Desenvolvimento Sustentável Mamirauá (IDSM). Está vinculada a outras duas importantes unidades de conservação, a RDS Mamirauá e o Parque Nacional de Jaú. Juntas formam o maior corredor ecológico de Floresta Tropical do mundo oficialmente protegido. Esta categoria de unidade de conservação é dividida em duas zonas, uma de proteção integral e outra de uso sustentável, formada por setores políticos que são instâncias locais de organização comunitária. O modelo procura articular pesquisas científicas ao conhecimento tradicional para o desenvolvimento social e econômico das populações que contribuem efetivamente para a manutenção da biodiversidade com práticas sustentáveis de manejo de recursos. Para maiores informações ver Queiroz 2005; Queiroz e Peralta 2006.

2 As poucas informações arqueológicas sobre o Lago Amanã já destacam a pre- 
sença dessas concentrações. Este é o caso por exemplo do estudo de Henri Feriz sobre cerâmicas coletadas nas adjacências de Tefé e ao longo do rio Japurá. No texto é citado um sítio localizado às margens do lago Amanã que na ocasião mostrava "urnas funerárias aflorando à superfície" (Feriz 1963:150-151).

${ }^{3}$ Processo IPHAN nº 01490.0000551/2008-27

${ }^{4}$ Como é comum entre os rios Amazônicos, o rio conhecido como Japurá é conhecido como Caquetá no território colombiano.

${ }^{5} \mathrm{O}$ sítio Boa Esperança, às margens do Lago Amanã, possui características similares às que serão descritas ao longo do texto.

6 Durante todo o texto utilizamos "fase" como um instrumento cronológico, onde são reconhecidos conjuntos com características próprias para manufatura de artefatos e/ ou ocupação do território, em nenhum momento relacionada a grupos étnicos ou populações específicas.

${ }^{7}$ A fase Caiambé é contemporânea às fases Manacapuru e Paredão, encontradas em sítios da Amazônia Central. Possui cerâmicas temperadas com cauixi (filo Porifera) e caraipé (Licania spp), com ênfase na decoração incisa aplicada em bordas flangeadas, bem como presença constante de pintura. As duas datas disponíveis para a fase são de $640 \pm 60$ e $730 \pm 60$ D.C (Hilbert 1968).

${ }^{8}$ Utilizamos a nomenclatura feição segundo a definição de Castro (2009:106-7) para os contextos da Amazônia Central: “o conceito de feição está relacionado a evidências antropogênicas de intervenção em sub-superfície, quase sempre verticalmente dispostas na estratigrafia e que não possuem uma estrutura física ou arquitetônica delimitada".

${ }^{9}$ Outros autores preferem o termo bioarqueologia, mas esta normalmente enfatiza as análises de paleopatologia em laboratório.
${ }^{10}$ A urna foi submetida ao tratamento de restauração com desmontagem, limpeza a seco, processo de estabilização da peça com aplicações de consolidantes e remontagem.

${ }^{11}$ Cortical e esponjoso correspondem a partes diferentes de um mesmo osso; cortical é a parte externa, mais densa, enquanto que esponjoso é a parte interna e porosa, portanto mais frágil.

${ }^{12}$ Entretanto, visto que a presença de material polícromo nas camadas superficiais de parte dos sítios encontrados é possível que existam urnas similares às das fases Guarita ou Napo que ainda não foram encontradas.

\section{REFERÊNCIAS}

Arroyo-Kalin, M. 2010. A domesticação da paisagem: os solos antropogênicos e o formativo na Amazônia, in Arqueologia Amazônica. Editado por E. Pereira e V. Guapindaia, pp. 879-908 Vol.2. Belém: Museu Paraense Emilio Goeldi.

Barreto, C. 2008. Meios míticos de reprodução social: Arte e estilo na cerâmica funerária da Amazônia antiga. Tese de Doutorado, Museu de Arqueologia e Etnologia, Universidade de São Paulo, São Paulo.

2010. Cerâmica e complexidade social na Amazônia antiga: uma perspectiva a partir de Marajó, in Arqueologia Amazônica. Editado por E. Pereira e V. Guapindaia, pp. 193-212, Vol.1. Belém: Museu Paraense Emilio Goeldi. 2011a. Corpo e identidade na Amazônia antiga: Um estudo comparativo de estatuetas cerâmicas. Projeto de Pós-Doutorado. Museu de Arqueologia e Etnologia, Universidade de São Paulo, inédito.

. 2011b. Entre estatuetas, urnas e corpos: os encantamentos dos objetos antropomorfos na arqueologia amazônica. In: Seminário Tecnologia, Arte e Patrimônio na Amazônia: Abordagens críticas sobre aquisição e transformação de conhecimentos, 2011 dez 14-15, São Paulo, pp. 5. 
Binford, L.R. 1991. A tradução do registro arqueológico, in Em Busca do Passado, pp. 2836, Lisboa: Europa/América.

Brochado, J. P. 1984. An Ecological Model of the Spread of Pottery and Agriculture in the Eastern South America. Tese de Doutorado. Universidade de Illinois, EUA.

Castro, M. W. 2009. A cronologia dos sítios Lago do Iranduba e Laguinho à luz das hipóteses de ocupação humana para a Amazônia central. Dissertação de Mestrado. Programa de Pós Graduação em Arqueologia, Museu de Arqueologia e Etnologia, Universidade de São Paulo, São Paulo.

Cavelier, I., C. Rodriguez, L. Herrera, G. Morcote e S. Mora. 1995. No solo de caza vive el hombre: Ocupación del bosque Amazónico, Holoceno temprano, in Ámbito y ocupaciones tempranas de la América Tropical. Editado por I. Cavelier e S. Mora, pp. 2744. Bogotá: Fundación ERIGAIE - Instituto Colombiano de Antropologia.

Chaumeil, J-P. 1997. Entre la memoria y el olvido: Observaciones sobre los ritos funerarios en las tierras bajas de América del Sur. Boletín de Arqueología PUCP 1:207-232.

Childe, G. 1929. The Danube in Prebistory. New York: Alfred A. Knopf.

Costa, B. L. 2008. Levantamento Arqueológico na RDS Amanã. UAKARI 4(2): 7-19.

. 2009. Plano de Manejo do Patrimônio Arqueológico Existente na RDS Amanã. Instituto de Desenvolvimento Sustentável Mamirauá. Relatório Científico apresentado ao CNPq. Inédito.

2011. Boa Esperança e Bom Jesus: O 'universo borda incisa' na RDS Amanã - Estado do Amazonas. Relatório de Qualificação, Museu de Arqueologia e Etnologia, Universidade de São Paulo, Brasil. Inédito.

Costa, M. L, H. Behling, K. Suguio, N. Kämpf e D. C. Kern. 2009. O ambiente amazônico. Paisagens Amazônicas sob a ocupação do homem pré-historico : Uma visão geológica, in As Terras Pretas de Índio da Amazônia: sua caracterização e uso deste conhecimento na criação de novas áreas. Editado por W.G. Teixeira, D. C. Kern, B. E. Madari e W. Woods, pp. 15-38. Manaus: Embrapa Amazônia Ocidental.

Duday, H. 2005. L'archéotanatologie ou l'archéologie de la mort, in Objets et méthodes en paleoanthropologie. Editado por O. Dutour, J. J. Hublin \& B. van der Meersch, pp.153216. Paris: Comité des travaux historiques et scientifiques (CTHS).

Eden, M. J., W. Bray, L. Herrera \& C. McEwan. 1984. Terra Preta soils and their archaeological context in the Caquetá basin of southeast Colombia. American Antiquity 49(1): 125-140.

Erickson, C. 2003. Historical ecology and future explorations, in Amazonian Dark Earths: Origin, Properties, Management. Editado por J. Lehmann, D. Kern, B. Glaser \& W. Woods, pp. 455-500. Dordrecht: Kluwer Academic.

Evans, C. \& B. Meggers. 1968. Archaeological investigations on the rio Napo, eastern Ecuador. Washington: Smithsonian Institution Press.

Feriz, H. 1963. The ceramics of TeféAmaná: A Contribution to the Archeology of the Amazon. Ethnos 28:147-176.

Gomes, D. M. C. 2010. Os contextos e os significados da arte cerâmica dos Tapajós. Arqueologia Amazônica. Editado por E. Pereira e V. Guapindaia, pp. 213-234. Vol.1. Belém: Museu Paraense Emilio Goeldi.

Gomes, J. 2011. 'Is it true that this place used to be an Indian village?' Ceramic analysis and preliminary chronology of Boa Esperança archeological site, located in Amanã SDR, Mid-Solimões River, State of Amazonas, Brazil. UAKARI 7(2): 7-20.

Guapindaia, V. C. 2008. Além da margem do 
rio: as ocupações Konduri e Pocó na região de Porto Trombetas, $P A$. Tese de Doutorado. Museu de Arqueologia e Etnologia de São Paulo, Universidade de São Paulo.

Guapindaia, V. \& A. L. C. Machado. 1997. O Potencial Arqueológico da Região do Rio Maracá/Igarapé do Lago (AP). Boletim do Museu Paraense Emilio Goeldi. Antropologia (Cessou em 2002), Belém, v. 13 n 1, pp. 67-102.

Hanke, W. 1959. Archäologische funde im oberen Amazonasgebiet. Archiv für Völkerkunde, n 14; pp. 31-66.

Heckenberger, M. J. 2001. Estrutura, história e transformação: a cultura xinguana na longue durée, 1.000-2.000 d.C, in Os Povos do alto Xingu. História e cultura. Organizado por B. Franchetto \& M. Heckenberger, pp. 21-62, Rio de Janeiro: Editora UFRJ.

Herrera, L., W. Bray \& C. McEwan. 1980-81. Datos sobre la arqueología de Araracuara (Comisaría del Amazonas Colombia). Revista Colombiana de Antropología XXIII. pp.184-251.

Hilbert, P. P. 1962. Preliminary results on the Japura River. Middle Amazon. Akten des $34^{\circ}$ Internationalen Amerikanistenkongresses, pp. 465-470.

1968. Archaologisch Untersuchungen am Mittleren Amazonas. Berlin: Dietrich Reimer Verlag.

Hilbert, P. P. \& K. Hilbert. 1980. Resultados preliminares da pesquisa arqueológica nos rios Nhamundá e Trombetas, Baixo Amazonas. Boletim do Museu Paraense Emílio Goeldi, Nova Série, Antropologia 75: 25-42.

Kern, D. C., N. Kämpf, W. I. Woods, W. M. Denevan, M. L. da Costa, F. J. L. Frazão \& W. Sombroek, 2009. As terras pretas de índio na Amazônia. Evolução do conhecimento em Terra Preta de Índio, in As Terras Pretas de Índio da Amazônia: sua caracterização e uso deste conbecimento na criação de novas áreas. Editado por W.G. Teixeira, D. C. Kern, B. E. Madari \& W. Woods. Manaus: Embrapa Amazônia Ocidental.
Lathrap, D. 1970. The Upper Amazon. London: Thames and Hudson.

Lima, H. P. 2008. História das caretas: A tradição borda incisa na Amazônia central. Tese de Doutorado. Museu de Arqueologia e Etnologia, Universidade de São Paulo.

Lima, H., E. G. Neves \& J. Petersen. 2006. A fase Açutuba: Um novo complexo cerâmico na Amazônia central. Arqueologia Suramericana 2(1): 26-52.

Machado, J. S. 2005. Montículos artificiais na Amazônia central: um estudo de caso do sítio Hatahara. Dissertação de Mestrado, Museu de Arqueologia e Etnologia, Universidade de São Paulo.

2007. O significado dos sistemas tecnológicos: classificando e interpretando o vestígio cerâmico. Arqueologia Sul Americana 3(1): 62-83.

Machado, L. C. 2006. Os sepultamentos, contextos arqueológicos e dados bioesqueletais. Boletim do Instituto de Arqueologia Brasileira (IAB) 12: 25-33.

Meggers, B. \& C. Evans. 1957. Archeological investigations at the mouth of the Amazon. Bulletin 167. Washington D.C.: Smithsonian Institution.

Mendonça de Souza, S. M. F. 2010. O silêncio bioarqueológico da Amazônia: Entre o mito da diluição demográfica e a diluição biológica na floresta tropical. Arqueologia Amazônica. Editado por E. Pereira e V. Guapindaia, pp. 425-445, Vol.1. Belém: Museu Paraense Emilio Goeldi.

Mendonça de Souza, S. M. F., V. Guapindaia \& C. D. Rodrigues. 2001. A necrópole Maracá e os problemas interpretativos em um cemitério sem enterramentos. Boletim do Museu Paraense Emílio Goeldi 17(2):479-520.

Müller, L. M.; Souza, S.M.F.M. 2011. Enterramentos Guarani: problematização e novos achados, in Antes do Oeste Catarinense: arqueologia dos povos indígenas. Organizados 
por M. Carbonera e P. Schimitz, pp. 167218, v. 1, Chapecó: Argos.

Moraes, C. P. 2006. Arqueologia na Amazônia Central vista de uma perspectiva da região do Lago do Limão. Dissertação de Mestrado, Museu de Arqueologia e Etnologia, Universidade de São Paulo, Brasil.

2010a. Aldeias circulares na Amazônia Central: um contraste entre fase Paredão e fase Guarita, in Arqueologia Amazônica. Editado por E. Pereira e V. Guapindaia, pp.582-604. Vol.2. Belém: Museu Paraense Emilio Goeldi.

2010b. Arqueologia regional na Amazônia Central: A fase Paredão e sua inserção no contexto pré-colonial Amazônico. Qualificação de Doutorado, Museu de Arqueologia e Etnologia, Universidade de São Paulo, Brasil. Inédito.

Moraes, C. P. \& F. O. Lira. 2009. Incisões, Ponteados, Acanalados e Policromia: como podemos utilizar esses ícones para inferir fronteiras e influências culturais. In: XV Congresso da Sociedade de Arqueologia Brasileira, 2009, Belém. XV Congresso da Sociedade de Arqueologia Brasileira - Livro de Resumos. Belém : Tribuna. pp. 12-12.

Neves, E. G. 1998. Twenty years of Amazonian Archaeology in Brazil. Antiquity 72: 625- 632.

1999. Changing perspectives in Amazonian archaeology, in Archaeology in Latin America. Editado por G. Politis e B. Alberti, pp.216-243. Londres: Routledge.

2000. Levantamento arqueológico na área de confluência dos rios Negro e Solimões, estado do Amazonas. Relatório de Atividades apresentado à FAPESP. Museu de Arqueologia e Etnologia, Universidade de São Paulo. Inédito.

2010. A arqueologia da Amazônia central e as classificações na Arqueologia Amazônica, in Arqueologia Amarônica. Editado por E. Pereira e V. Guapindaia, pp. 561-579. Vol.2. Belém: Museu Paraense Emílio Goeldi. 2011a. Archaeological cultures and past identities in precolonial central Amazon. Ethnicity in ancient Amazonia: Reconstructing past identities from archaeology, linguistics, and ethnohistory. Organizado por A.Hornborg \& J.Hill, pp. 31-56. Boulder: University of Colorado Press.

2011 b. El nacimiento del Presente Etnográfico': la emergencia del patrón de distribución de sociedades indígenas y familias lingüísticas en las tierras bajas sudamericanas durante el primer milenio d. C., in Por donde hay soplo: Estudios amazónicos en los países andinos. Organizado por J. P. Chaumeil; Ó. E.de Rivero \& M. C. Chaparro, pp. 39-65. Lima: Instituto Francés de Estudios Andinos.

Neves, E. G., J. B. Petersen, R. N. Bartone, C. A. Silva. 2003a. Historical and sociocultural origins of Amazonian Dark Earths, in Amazonian Dark Earths: Origins, properties, manegement. Editado por J. Lehmann, D. Kern, B. Glaser \& W. Woods, pp. 29-50. Dordrecht: Kluwer Academic Publishers.

Neves, E. G., M. Arroyo-Kalin, R.Bartone, F. W. S. Costa, P. Bayod Donatti, B. Glaser, J. S. Machado, C. J. Munita, L. F. E. Lima, J. B. Petersen, H. P. Lima, L. Rebellato, C. A. da Silva, E. A. Soares. 2003b. Relatório de Atividades do Projeto Levantamento Arqueológico da área de Confluência dos Rios Negro e Solimões, Estado do Amazonas: Continuidade das Escavações, Análise da Composição Química e Montagem de um Sistema de Informações Geográficas. Relatório Científico apresentado à FAPESP.

Queiroz, H. 2005. Reserva de Desenvolvimento Sustentável Mamirauá. Estudos Avançados 19(54):183-203.

Queiroz, H., Peralta, N. 2006. Reserva de Desenvolvimento Sustentável: Manejo integrado dos recursos naturais e gestão participativa, in Dimensões humanas da biodiversidade, Organizado por I. Garay \& B. K. Becker, pp. 447-476. Petrópolis: Vozes. 
Rapp Py-Daniel, A. 2010. O que o contexto funerário nos diz sobre populações passadas: o sítio Hatahara. Arqueologia Amazônica. Editado por E. Pereira e V. Guapindaia, pp. 629-653. Vol.2. Belém: Museu Paraense Emilio Goeldi.

Rebellato, L. 2007. Interpretando a variabilidade cerâmica e as assinaturas fisicicas e quimicas no solo no sitio arqueológico Hatahara/ AM. Dissertação de Mestrado, Museu de Arqueologia e Etnologia, Universidade de São Paulo, São Paulo, Brasil.

Rostain, S. 2010. Pre-Columbian earthworks in coastal Amazonia. Diversity 2:331-352.

Schaan, D. P. 2001. Estatuetas antropomorfas marajoara: o simbolismo de identidades de gênero em uma sociedade complexa amazônica. Boletim do Musen Paraense Emílio Goeldi.Série Antropologia., 17(2):23-63.

.2003. A ceramista, seu pote e sua tanga: identidade e papéis sociais em um cacicado marajoara. Revista de Arqueologia 16:31-45.

2004. The Camutins chiefdom: Rise and development of social complexity in Marajo Island. Tese de Doutorado, Departamento de Antropologia, Universidade de Pittsburgh, USA.

Shepard, G. 2001. Relatório Preliminar sobre sítio arqueológico e cemitério indígena na Reserva Amanã. Manaus: $1^{a}$ Superintendência do IPHAN. Inédito.

Shepard, A. O. 1956 Ceramics for the Archaeologist. Washington: Carnegie Institution.

Schiffer, M. 1987. Formation process of the archaeological record. Albuquerque: University of New Mexico.

Schmidt, M. J. 2010a. Reconstructing tropical nature: Pre-historic and modern anthrossols (Terra Preta) in the Amazon Rainforest, Upper Xingu River, Brazil. Tese de Doutorado, Departamento de Geografia, Universidade da Flórida, USA.

2010b. Historical landscapes in the neotropics: A model for pre-historic anthro- sol (terra preta) formation in the upper Xingu, in Arqueologia Amarônica. Editado por E. Pereira e V. Guapindaia, pp. 853-878, Vol.2. Belém: Museu Paraense Emilio Goeldi.

Teixeira, W. G., G. C. Martins, R. S. Macedo, A. F. Neves Junior, A. Moreira, V. M. Benites \& C. Steiner. 2009. As proprioedades físicas e hídricas dos horizontes antrópicos das Terras Pretas de Índio na Amazônia central, in As Terras Pretas de Índio da Amazônia: sua caracterização e uso deste conhecimento na criação de novas áreas. Editado por W.G. Teixeira, D. C. Kern, B. E. Madari \& W. Woods, pp. 242-250. Manaus: Embrapa Amazônia Ocidental.

von Hildebrand, E. 1976. Resultados preliminares del reconocimiento del sitio arqueológico de la Pedrera (Comisaría del Amazonas, Colombia). Revista Colombiana de Antropología XX: 145-176.

Woods, W. 2009. Os solos e as ciências humanas: Interpretação do passado, in $A s$ Terras Pretas de Índio da Amazônia: sua caracterização e uso deste conbecimento na criação de novas áreas. Editado por W.G. Teixeira, D. C. Kern, B. E. Madari \& W. Woods, pp. 62-71. Manaus: Embrapa Amazônia Ocidental.

Recebido em 17/02/2012.

Aprovado em 14/03/2012. 